International Journal of Engineering \& Technology, $7(2.13)(2018) 255-258$
International Journal of Engineering \& Technology
Website: www.sciencepubco.com/index.php/IJET
Research Paper

\title{
Investigation of effects associated with educational environment and equipment in clinical learning of speech therapy
}

\author{
Hossein Gerivani ${ }^{1}$, Hossein Mobaraki ${ }^{2}$, Mohammad Kamali $^{3}$, Ali Ghorbani ${ }^{4}$ \\ ${ }^{1-}$ Master of Rehabilitation management, School of Rehabilitation, Iran University of Medical Sciences \\ ${ }^{2}$ Assistant Professor in Health Care Administration, School of Rehabilitation, Iran University of Medical Sciences \\ 3-Professor, School of Rehabilitation, Iran University of Medical Sciences \\ ${ }^{4}$ Lecturer, , School of Rehabilitation, Iran University of Medical Sciences \\ *Corresponding author E-mail:
}

\begin{abstract}
Aim: This study aim to investigate educational environment and equipment and their effects on clinical learning of speech therapy. Investigation method: Content analysis was employed for conduct this research, for which 13 university students, 6 trainers, and 6 therapists practicing speech therapy were selected through purposive sampling. Data was collated using in-depth semi-structured interviews and also group discussion sessions and analyzed using Colaizzi method.

Findings: The results of current study showed that educational environment and equipment are contributing factors to quality of clinical learning through speech therapy. Findings of the study were classified as two main concepts i.e. physical space, and equipment and software, each of which was in turn divided into smaller categories of concepts.

Conclusion: The findings of the study revealed that physical space of clinical learning and use of therapeutic equipment in such spaces are contributing factors to clinical learning associated with speech therapy.
\end{abstract}

Keywords: Environment and Equipment; Clinical Learning; Speech Therapy.

\section{Introduction}

Clinical learning can be defined as activities that accelerate learning process in clinical environment in which trainer and student are equally involved and it aim to create measurable changes in students in order to perform clinical care, in a way that upon completion of the training course students should be able to use their acquired skills with adequate efficiency [1]. Clinical learning is important in that it provides real opportunities for students to prepare themselves for future clinical environments. [2-3]. This training depends on several variables including factors related to teacher, student and learning environment [4]. Clinical learning environment is defined as an interactive and sophisticated network of forces that influence the students' results through clinical learning (5). Unlike classroom training, clinical learning occurs in a sophisticated, social environment that is affected by various factors (6). It should be noted that a large part student learning occur in clinical environments and several factors such as quality of trainer's teaching, quality of supervising the process of learning, amount of educational equipment available in the environment and psychological atmosphere of environment affect student's learning process $(7,8)$. In a clinical environment, the focus of learning is on real issues which arising in a professional working place and learners are motivated due to this relationship and their active participation in the environment and this is the only environment where skills such as obtaining medical history, physical examination, clinical reasoning, decision making, sympathizing, and professional commitment can be learned integrally and completely (9). Clinical environment is one of important and critical factors in student's learning and the vital role of instructors is to prepare a suitable environment to expedite learning process [10]. Studies show that clinical teaching environment has numerous effects on students the most important of which include helping to shape their attitude, psychomotor skills, knowledge, problem-solving skills [11], clinical qualification, communications skills, and critical thinking skills [12]. In a study done in Yazd, 42-59 per cent of students believed that equipment available in units, both in terms of quality and quantity, available devices and patients and clients seldom match their theoretical knowledge and nursing skills (13). In another study by Abedini et al 71 per cent of student considered facilities and another 41 per cent thought of lack of space and learning tools as the problems they face during their internship (10). Complex and critical role of clinical internship in medical sciences investigated in studies done in other countries have also been confirmed and recently more researchers pay particular attention to this matter. A review of studies done in other countries also revealed that providing various learning opportunities, receiving appropriate feedback by teachers and atmosphere in clinical environment are crucial factors in clinical learning [14 15]. A study in Taiwan, titled "Investigation of Services in Nursing Education" stated that a suitable environment for practicing skills and having physical and environmental security are important effective prerequisites in clinical learning which should be provided by educational institutes and should meet current standards. May believes that various factors affect student learning and providing devices and equipment in units for accelerating learning process is one of these factors (16). Considering the importance of clinical environment, Lambert believes that clinical environment is considered a crucial 
place for students and providing a suitable (learning) environment is one the predictors of effectiveness of clinical learning, thus paying attention to this matter has a considerable effect on clinical learning (17). Although students' learning experience from clinical environment has been improving and they are generally satisfied with the results, aforementioned problems are still extent which is probably because controlling clinical learning environment is difficult. Recent studies have shown that students' expectations of providing learning opportunities, acquiring clinical skills, sense of belonging and respect are not met (18). Considering the importance of internship courses and due to direct interaction of students during these courses, identifying current situation deficiencies from the viewpoint of those involved in them can provide a basis for improving the current situation and problems. Therefore, the need for conducting scientific studies in order to identify these gaps correctly and systematically can be felt. In this regard, this study aims to investigate the effects of physical environment and equipment in clinical learning in the field of speech therapy.

Investigation method: This is a quality study and is based on content analysis for which purposive sampling was employed. Sample of the study includes professors, students, therapist in the field of speech therapy in the city of Tehran. To collect necessary data for this study, 6 semi-structured interviews with instructors, 6 semistructured interviews with therapist, 3 groups interviews ( with 4 people in each group) and one in-depth individual interview with one of the students were conducted. In order to collect adequate information, senior students of BSc in clinical field were selected for interview. Therapist selected for interview graduated no more than five years ago because it was likely that methods and models used for older graduate students were different from those used for more recent graduate students. Instructors selected for interview had at least one-year experience of working in clinical environment and were operating in this field at the time of study.

Size of sample was determined by data saturation and after saturation, sampling was completed. Colaizzi method was also used to analyze the data.

Findings: After conducting interviews and analyzing data, two main concepts of physical space, and equipment and software with regard to environment and educational facility were obtained.

Physical space of clinical learning:

This concept in turn consists of other concepts, which refer to physical characteristics of clinical environment and therapy rooms: allocated room, change in student's attitude, mundane therapy rooms, lack of acoustic property of therapy rooms and mirror rooms.

Allocated rooms:

One of the interviewees believed that rooms allocated for speech therapy should at least have the expected standards:

"Most university students have a perception of clinics one way or another. The actual place should be in complete contrast with what they have in mind. Of course, it can be different but it should completely shatter that perception. Something should be done about the place (clinic) so that it represents the services it provides. Perhaps if these matters specialized, then it may help. (Instructor 2)

Another participant also considers allocating room for speech therapy a factor that can alter the attitude of clients and families using speech therapy:

"In one of the schools, for example, a room which was previously used as pantry and the label on the door read "pantry". How would you feel (if you saw that)? This can have a lot of effect on how you view your field of study. Alternatively, even suppose I asked one of the parents of the children I am working with to come to school. Would he take the therapist (me) seriously if he sees such a place? (Therapist 2)

One of the students said that allocating emergency room of a hospital for speech therapy and lack of necessary facilities was the main reason for why his clients did not make much progress:

"We didn't have any facilities at the hospital. We held our sessions in an emergency room. We had nothing. Only a (internship) card. It was possible to interact with children. There were no tools. If they do not have any facilities, why do they take students there, and at the end semester professors complain that our case has not made much progress. There should be something so that we can communicate with children." (Group discussion 3)

Another student believed that some therapy rooms are not suitable for children:

"some of them (rooms) did not have playroom. For example, sometimes we need to play with children. For example, you need to play with a two and a half year old but you can't do it sitting at a desk. This makes it difficult. (Group discussion 2)

Changing student's attitude:

Another factor related to internship environment is the effect it has on student's attitude and his/her self-confidence:

"When a student spends his internship period in a hospital he/she has more self-confidence because they can see disorders which doctors deal with more often but in a welfare center or school you would feel like a teacher or a kind of boredom which requires not much activity" (Therapist 1 )

"Personally I think working environment has the most effect on our motivation. I mean whether I spend my internship in a hospital or a school makes a big psychological difference. When I am in a hospital you have to deal with patients who or socially or economically at a higher level and this can boost your confidence but when visit patients who are either physically or socially lower this can have negative effect on your morale (Therapist 2)

"I spent one semester in a school for children with special needs. In my opinion, schools are not a good place for internship. There are not any facilities and therapists are not taken seriously. (Therapist 3) Mundane therapy rooms:

According to one of participating students, mundane atmosphere of therapy rooms leads to early fatigue for both therapist and clients:

"Look, college classrooms are really dull and dismal. Every time I come out of the classrooms I feel absolutely tired. Patients who come there don't find them interesting either so they don't really cooperate with us. Naturally, if therapy room is interesting, the patients are more willing to cooperate" (Group discussion 3)

Another Interviewee also mentioned this problem:

"I, as an adult, felt bored in therapy rooms let alone children. I even remember that a mother of one of patients said: why is this place like this, it scares children and decided not to show up again. (Therapist 5)

Lack of acoustic property of therapy room:

As one of interviewees said, lack of acoustic property of therapy room can interfere with the process of therapy sessions:

"Therapy rooms are close to one another so when you ask your client a question in this room the other in the next room answers the question. This is not good. (Group discussion 1)

Another interviewee also mentioned this problem:

"When I was in a school for children with special needs, therapy rooms were very crowded. I mean, you could hear noises from everywhere, there was a lot of commotion in school corridor, which distract patient's attention from the task they were asked to do. I was the therapist and even I couldn't concentrate" (Therapist 3) Building mirror rooms:

Another interviewee mentioned that making mirror rooms in clinical centers helps improve the quality of therapy session and parents' learning:

"As far as I know, in some foreign countries they have mirror rooms where parents wait and they can observe how therapist is working with their children without interfering with therapy process and learn very well. If there were such rooms children would have more time" (Therapist 5)

Equipment and software programs:

This concept includes secondary concepts of changing client's attitude, teaching with cards, necessity of using software programs in order to increase efficiency of therapy.

Changing client's attitude:

As some interviewees mentioned, one of the effects of using equipment and software programs in clinical environment is that it can change clients' attitude about therapy and speech therapy: 
"About using equipment I should say when we use these devices people have a better attitude toward this field? For example, physiotherapy has become popular and known to people thanks to using such devices and equipment" (Therapist 4)

"Sometimes, when parents see a well-equipped therapy room it gives them the impression that because it is better-equipped so it should be better. Sometimes, people judge based on what they see" (Therapist 3)

"People often think that a task which is done using devices is better because they think it performs miracles." (Group discussion 1) Another interviewee also believed that using equipment especially for adult clients is very important:

"All devices may accomplish the same thing but one of them may help client, especially adult ones, trust you better and take your therapy seriously" (Group discussion 3)

Teaching with the help of cards:

One of the problems mentioned about using equipment is use of playing cards as therapy tools that some interviewees think that they are unsuitable for therapy:

"All we did was playing cards. I mean for all clients of any age therapists use cards and asked the name of different pictures on cards. Parents and families who saw that this for two sessions obviously would not pay therapy sessions anymore because they believe they can do it themselves." (Therapist 3)

Another interviewee believed that the purpose of therapy is more important than tools employed for therapy:

"In my opinion, equipment can be an effective factor but students who have performed therapy sessions and understand the purpose behind it doesn't care where they work and what tools they use." (Trainer 5)

Necessity of using software programs:

Using software programs in clinical environment was another factor, which, according to some, can help attract clients:

"Using equipment is definitely effective. Now we see that most equipment is provided in form of software programs, which is more helpful than those traditional forms, so to speak, and clients and their families who see that sometimes we use card and sometimes computer programs to work with clients prefer that we use computer programs or devices designed for various disorders. When devices are used in therapy it can have a more positive effect" (Therapist 1)

"Therapy centers that use computer programs for therapy are more appealing to both families and intern therapists who think that it is easier to do his/her job by simply pushing a button (on a keyboard) (Trainer 4)

Another teacher believes that students' ideas can be used to make new software programs related to the field:

"Students who have some ideas about software programs should be encouraged to make them. In fact, this could be done through graduate and even postgraduate projects that students design new software programs for various purposes and various disorders. We need to respect ideas and allow them to flourish and allocate some fund for these student projects which can be useful. We can ask students to design software programs, for example, for auditory stimulation, auditory distinction and or teaching names. Students can help in this area and even register their inventions and produce them in large scale." (Teacher 6)

Increasing therapist's efficiency:

As one of the interviewees mentioned, another positive aspect of using equipment is that therapist will be less tired and this reduces the health concerns associated with their job and as a result therapist will be more efficient during therapy sessions:

"Computer (programs) should be used in all therapy rooms. I mean therapists should realized that they can use their energy to teach children in a different way." (Teacher 6)

"We can use all tools and equipment and even software programs. The good thing is we won't be so tired and our job will be taken more seriously by clients and well, this is obvious." (Group discussion 2)
"We have 45 minutes to work with children. To preserve the health of our speech organs, we should not waste a lot of energy and we can use various tools." (Teacher 6)

Table 1: Man Concepts of Educational Facilities and Environment and Their Subcategories

\begin{tabular}{|c|c|}
\hline Main concepts & subcategories \\
\hline $\begin{array}{l}\text { physical space in } \\
\text { clinical learning }\end{array}$ & $\begin{array}{l}\text { allocated rooms - changing student attitude - } \\
\text { mundane therapy rooms }\end{array}$ \\
\hline $\begin{array}{l}\text { lack of acoustic } \\
\text { property of ther- } \\
\text { apy rooms }\end{array}$ & mirror rooms \\
\hline $\begin{array}{l}\text { equipment and } \\
\text { software programs }\end{array}$ & $\begin{array}{l}\text { changing clients' attitude - Teaching with the } \\
\text { help of (playing) cards - necessity of using soft- } \\
\text { ware programs - Increasing therapists' efficiency }\end{array}$ \\
\hline
\end{tabular}

\section{Discussion}

Clinical learning environment is where students can hone their clinical skills in order to be able to enter the working society. Findings of this study showed that students' understanding and expectations of clinical learning environment is different from what exists in the real working environment. Lack of therapy rooms and unsuitable therapy area are among some of the problems mentioned earlier. Lack of suitable learning space in some therapy centers and lack of appealing physical appearance of some clinics is one of the findings of Dastghaybi et al (19) which is consistent with those of Mirzabaygi et al in which factors related to educational environment such as lack of facilities and suitable learning space received the highest scores (20). Findings of a study by Dehghani et al also confirm this issue (21). According to Ryan and Tomposon, therapist and environment have the highest influence on students during the first few days of clinical experience especially in the first educational center and the third most effective factor is clients which is higher that the factor of time (22).

As mentioned by participants of the study, lack of equipment in clinical environment is another component that affects the quality of clinical learning. Reza'ee et al also concluded in his study that clinical learning faces several problems including lack of learning space, lack of equipment and tools, low level of variety of disorders in patients in education centers and also increasing number of students (23) which is consistent with findings of Abdi et al (24). According to midwifery students in another study, there were several problems regarding environmental factors and facilities (25). In this regard, Del Aram reported that from nursing and midwifery students' point of view, lack of facilities is the most important problem in clinical learning (26).

Another finding of this study, which is only mentioned in few other studies, is the impact of environment and equipment in students' and clients' attitude toward speech therapy. Interviewees believed that therapeutic equipment in clinical learning environment can boost students' motivation and also encourage cooperation and change in attitude. Considering that this issue was mentioned in most interviews, that in addition to providing more suitable therapy environment and meeting students' expectations, using equipment and software programs in clinical environment also seem necessary. Based on the findings of this study, it is clear that physical environment of clinical learning and also employing therapeutic equipment in such environment can increase the quality of clinical courses of speech therapy, increase efficiency of such course and also lead to change in attitude of students and clients.

\section{Acknowledgement}

Researchers would like to thank Mrs. Kaviani and all professors, students and therapists who participated and helped with conducting this study. 


\section{References}

[1] Aghvami, m., Satisfaction Nursing Studentsl'of Internship at Zanjan Medical University 138. Journal of Medical Education Development, 2010. 3(4): 1-6.

[2] Lee, D.T., The clinical role of the nurse teacher: a review of the dispute. Journal of advanced nursing, 1996. 23(6): 1127-1134.

[3] Dunn, S.V. and B. Hansford, Undergraduate nursing students' perceptions of their clinical learning environment. Journal of advanced nursing, 1997. 25(6): 1299-1306.

[4] Hosseiny, N. and Z. Karimi, The situation of clinical education based on nursing students' opinion in Yasuj nursing and Midwifery School. Iranian Journal of Medical Education, 2005. 5(2): 171-175.

[5] Dunn, S.V., The development of a clinical learning environmen scale. Journal of advanced nursing, 1995. 22(6): 1166-1173.

[6] Chan, D.S. and W.Y. Ip, Perception of hospital learning environment: a survey of Hong Kong nursing students. Nurse education today, 2007. 27(7): 677-684.

[7] Parsell, G. and J. Bligh, Recent perspectives on clinical teaching Medical Education, 2001. 35(4): 409-414.

[8] Chan, D.S., Validation of the clinical learning environment inventory. Western Journal of Nursing Research, 2003. 25(5): 519 532.

[9] Spencer, J., ABC of learning and teaching in medicine: Learning and teaching in the clinical environment. BMJ: British Medical Journal, 2003. 326(7389): 591

[10] Abedini, S., et al., Clinical education problems: the viewpoints of nursing and midwifery students in Hormozgan University of Medical Sciences. Bimonthly Journal of Hormozgan University of Medical Sciences, 2009. 12(4): 249-253.

[11] McRobbie, C.J. and B.J. Fraser, Associations between studen outcomes and psychosocial science environment. The Journal of Educational Research, 1993. 87(2): 78-85.

[12] Ip ,W.Y. and D.S.K. Chan, Hong Kong nursing students' perception of the clinical environment: a questionnaire survey. International Journal of Nursing Studies, 2005. 42(6): 665-672

[13] Delaram, M. and T. Salehiyan, Productivity in clinical education from the nursing and midwifery students' viewpoint. Education Strategies in Medical Sciences, 2011. 4(2): 67-71.

[14] Löfmark, A. and K. Wikblad, Facilitating and obstructing factors for development of learning in clinical practice: a student perspective. Journal of advanced nursing, 2001. 34(1): 43-50.

[15] Andrews, G.J., et al., Professional roles and communications in clinical placements: a qualitative study of nursing students' perceptions and some models for practice. International Journal of Nursing Studies, 2006. 43(7): 861-874.

[16] May, N. and L. Veitch, Working to learn and learning to work: placement experience of Project 2000 nursing students in Scotland Nurse Education Today, 1998. 18(8): 630-636.

[17] Lambert, V. and M. Glacken, Clinical support roles: a review of the literature. Nurse education in practice, 2004. 4(3): 177-183.

[18] O'Driscoll, M., H. Allan, and P. Smith, Still looking for leadershipWho is responsible for student nurses' learning in practice? Nurse Education Today : $(r) r \cdot . r \cdot 1 \cdot, 212-217$.

[19] Dastgheibi M,Kamali M. Internal Elements and External Factor Affecting Physiotherapy Clinical, Journal of Research in Rehabilitation Sciences, Sci 2014; 10 (3): 393-407[Persian]

[20] Mirzabeygi, G., et al., The necessity for specialty education in nursing MS program: Viewpoints of the faculty members of School of Nursing and Midwifery in Iran. Iranian Journal of Medical Education, 2010. 9(3): 263-271.

[21] Dehghani, H., K. Dehghani, and H. Fallahzadeh, The educationa problems of clinical field training based on nursing teachers and last year nursing students view points. Iranian journal of medical education, 2005. 5(1): 24-33.

[22] Tompson, M.-A.M. and A.G. Ryan, Influences on students during their early fieldwork placements. Canadian Journal of Occupational Therapy, 1996. 63(3:173-182.

[23] Rezaee M, Occupational Therapy Students' Experiences of the First Fieldwork Education: AQualitative Study, Journal of Medical Education Development[Persian]

[24] Abdi, K., et al., Evaluation of Educational Situation of Rehabilitation Branches in Welfare and Rehabilitation University, from the Students' Viewpoint. Educational Year, 2003. 2004: 57-64.

[25] Omidvar, S., F. Bakouei, and H. Salmalian, Clinical education problems: the viewpoints of midwifery students in Babol Medical University. 2005.
[26] Delaram, M., Clinical education from the viewpoints of nursing and midwifery students in Shahrekord University of Medical Sciences. Iranian journal of medical education, 2006. 6(2): 129-135. 